\title{
A Health Production Approach to Bone Health in Kenya
}

\author{
Thomas Mutinda Muthama ${ }^{1 *}$, Stephen Kyalo Mutiso², Daniel M. Munguti ${ }^{3}$ \\ 1. The Nog Akudos Searchtripp, P.O Box 390-90131, Tala, Kenya \\ 2. School of Education, University of Nairobi, P. O. Box 92, KIKUYU - KIKUYU CAMPUS, Kenya \\ 3. Teachers Service Commission, P.O Box 762-90131, Tala, Kenya \\ * E-mail of the corresponding author: searchtripp@gmail.com
}

\begin{abstract}
Reduced density and quality in bones increase fracture risk, which becomes evident later in life through recognition of osteoporosis which is a skeletal disorder characterized by compromised bone strength, pre-disposing to an increased risk of fracture and is a global health problem that affects men as well as women. Shocks are inevitable to everyone everywhere and in the wake of shock of chronic/severe illness like Corona virus (Covid-19) which is infecting and affecting individuals worldwide and countrywide; the response may be negative or positive. The negative responses acts like additional shocks, hence focus will be on the positive responses (good reports) which are meant to counter the shocks and improve individuals and consequently household's welfare. In some cases covid-19 results to death of a household member, this calls for immediate response to the shock. During the outbreak of corona virus, many individuals have lost their employment and at such a time when loss of salaried employment or non-payment of salary results, individuals may need to respond to the shock positively. A time like this the health care facilities are overstrained with many hospitalizations as a result of day to day increase in the shocks (corona virus) and its associated shocks like loss of employment and death. Likewise, the governments' curfews have made individuals to experience business failure, limit their movements, reduce physical activity, and change their food and nutrition and as a result may affect their health outcomes. This study sought to establish the determinants of bone health, based on the health production approach by isolating the effects of response to shocks, and food and nutrition on bone health. The current study found that good report (positive response to shocks), exercising (through use of non-motorized transport), completing secondary education, taking wine, consuming fruits like apples, pineapples and melons and vegetables such as lettuce, cucumber and courgette, and increased consumption of peanut butter, tinned fish, and minced meat, chocolate and cheese significantly helps in improvement of bone health as they reduce bone fracture. However, bad reports deteriorate bone health, increased consumption of bread and corned beef significantly depletes bone health as they increase the occurrence of fracture. This study recommends that in order to improve individuals' bone health there is need to convey good reports especially during shocks like Covid-19. Individuals who have experienced non-agricultural household business failure due to the outbreak of corona virus, they need not to give up but ought to respond by starting a new business. For improved bone health, individuals also need to continually exercise by using non-motorized means of travel like walking or cycling; they may need to take a little wine especially as their age increases; and strengthening their bones through increased consumption of apples, pineapples and melons, lettuce, cucumber and courgette, peanut butter, tinned fish, and minced meat, chocolate and cheese.
\end{abstract}

Keywords: Bone Health, Health Production, Corona Virus, Covid-19, Response to Shocks, Food and Nutrition

DOI: $10.7176 / \mathrm{JHMN} / 85-15$

Publication date: January $31^{\text {st }} 2021$

\section{Introduction}

\subsection{Background of the study}

Reduced density and quality in bones increase fracture risk, which becomes evident later in life through recognition of osteoporosis as a "silent killer" (Naughton et al., 2017). Osteoporosis is a skeletal disorder characterized by compromised bone strength, with a consequent increase in bone fragility and susceptibility to fracture (Kim et al., 2019) and as Kruger and Wolber (2016) argued is a global health problem that affects men as well as women. It is a public health problem both in the medical and socioeconomic fields; presently, affecting more than 200 million people worldwide (Jang et al., 2017). These calls for new approaches and further research which is needed to identify diets, food components, sun exposure, sleep patterns, work shifts, and other modifiable factors that can impact one or more mechanisms in identifying differences in osteoporosis causes and incidences. Consuming adequate levels of calcium and vitamin D throughout life are critically important to an individual's bone health (US Department of Health Human Services, 2004), this is the case because vitamin D is important for good bone 
health as it aids in the absorption and utilization of calcium. De Jonge (2016) added that micronutrients such as vitamin A also play a role in bone remodeling, and through diet, vitamin A can be consumed as preformed retinol which is mainly present in foods from animal origin, such as liver, dairy products and eggs, whereas the provitamins are abundant in foods from plant origin such as fruits and vegetables. In relation to this Hyson (2011) added that fruits and vegetables provide nutrients that are thought to be associated with improved bone health (vitamin $\mathrm{C}$, potassium, magnesium, and vitamin $\mathrm{K}$ ) in addition to producing alkaline metabolites that might improve bone health by reducing calcium excretion.

\subsection{Problem statement}

Shocks are inevitable to everyone everywhere and in the wake of shock of chronic/severe illness like Corona virus (Covid-19) which is infecting and affecting individuals worldwide and countrywide; the response may be negative or positive. The negative responses acts like additional shocks, hence focus will be on the positive responses (good reports) which are meant to counter the shocks and improve individuals and consequently household's welfare. The positive response varies in different aspects including receiving help from government, local and international non-governmental organizations (NGO). In some cases the covid-19 results to death of a household member, which calls for immediate response to the shock with stern actions like seeking spiritual help from religious institutions including prayers, sacrifices, or even consulting a diviner. During the outbreak of corona virus, many individuals have lost their employment and at such a time when loss of salaried employment or non-payment of salary results, individuals ought to positively respond to the shock by various aspects even if being deployed or starting a new business. A time like this the health care facilities are overstrained with many hospitalizations, resulting from day to day increase in the shocks (corona virus) and its associated shocks like loss of employment, business failure and death. Likewise, the governments' curfews have made individuals to limit their movements, reduce physical activity, and change their food and nutrition and as a result may negatively affect their health outcomes.

\subsection{Objective of the study}

To establish the production of bone health by isolating the effects of response to shocks, and food and nutrition on bone health.

\section{Methodology}

\subsection{Data}

The study used secondary data from the Kenya Integrated Household Budget Survey (KIHBS), 2005/2006", which was the first major household survey to be implemented under the National Statistical System (NSS) programme and is the largest and most unique sample survey ever undertaken by the Central Bureau of Statistics (CBS). The survey covered all the 70 districts including rural and urban clusters with data being collected from all arid and semi-arid areas for the first time in a decade. The survey was conducted over a period of 12 months, which covers all possible seasons. The sampling design involved a number of stages. In the first stage, 1,343 clusters were stratified by district (and by both urban and rural areas within each district) comprising 861 rural and 482 urban clusters. In the second stage, 10 households were randomly selected with equal probability in each cluster to give a total sample of 13,430 households, producing a total sample size of 8,610 in rural area and 4,820 in urban areas. The third stage involved calculation of sampling selection probabilities of each KIHBS household, which are used to derive sampling weights needed to compute unbiased estimates and statistics. KIHBS used both diary and recall methods in collecting household consumption and purchase information.

\section{Principal Components Analysis (PCA)}

This study used Principal Component Analysis (PCA) to create index variables (components) through reduction from a set of three variables. This made it possible to identify the variables that accounted for most of the variance in production of bone health. The study computed the component loadings, which were the correlation coefficients between the variables and factors. The PCA determined the underlying structures for measures on the following three variables: health conditions and sought medical services, shocks and response to the shocks, and food and nutrition. 


\subsection{Principal Component Analysis for Health Conditions and Sought Medical Services}

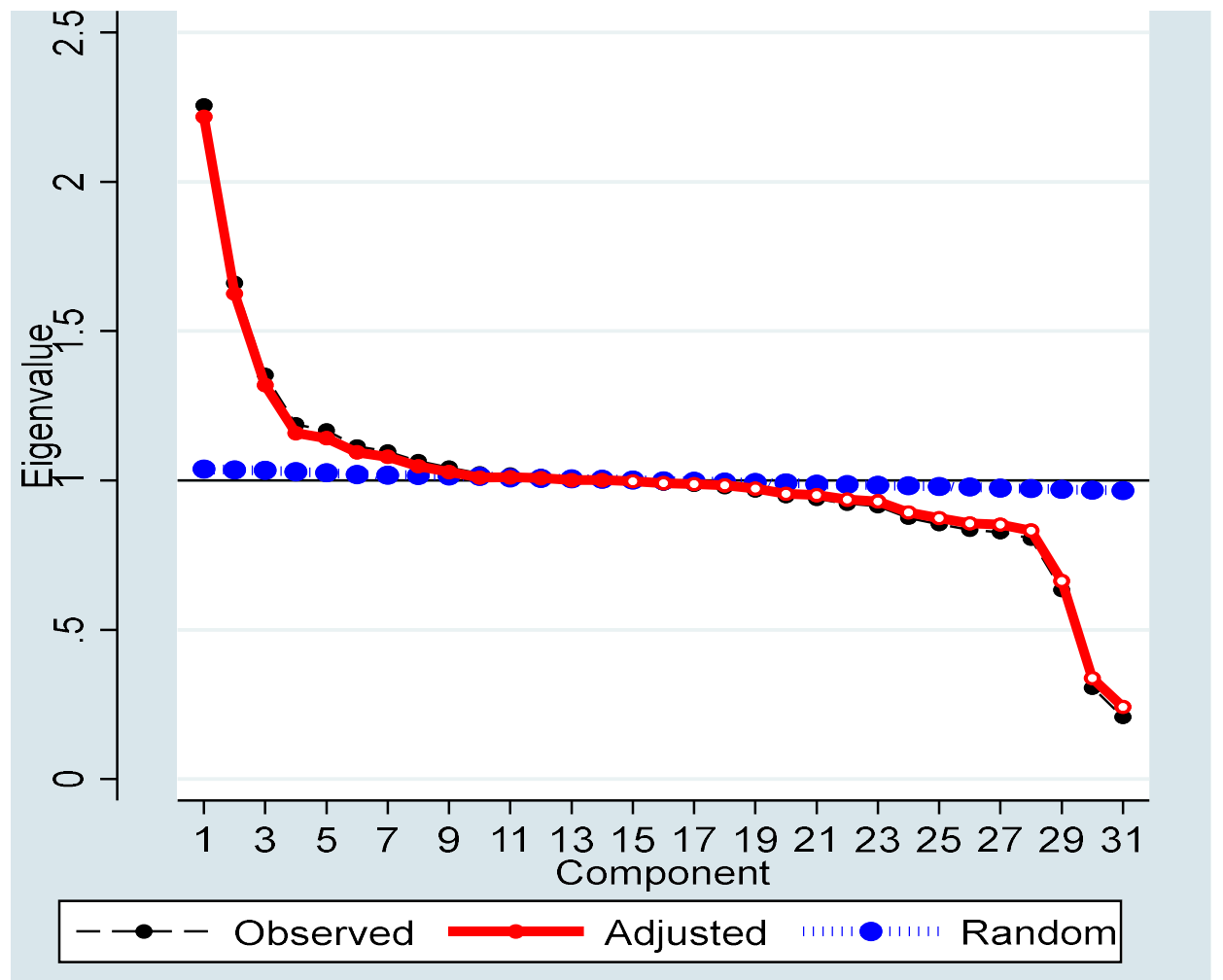

Figure 1: Horn's parallel analysis for Health Conditions and Medical Services

After extracting all the principal components, the Horn's parallel analysis was used to determine the number of components to retain for rotation and interpretation as illustrated in figure 1 . The components were rotated using a Varimax (Kaiser) rotation. This criterion produced nine components and was included on the grounds that they represent important aspects of the various health conditions and sought medical services and could conveniently be interpreted. The highest loadings on each component were highlighted and the interpretation of component is based on them. For the health conditions and sought medical services, the nine components conveyed $38.53 \%$ of the total variation of the set of 31 original variables.

Table 1: Principal Component Analysis for Health Conditions and Sought Medical Services

\begin{tabular}{|c|c|c|c|c|c|c|c|c|c|c|}
\hline Variable & Comp1 & Comp2 & Comp3 & Comp4 & Comp5 & Comp6 & Comp7 & Comp8 & Comp9 & Explained \\
\hline $\begin{array}{l}\text { Chronic } \\
\text { Malaria/Fever }\end{array}$ & 0.0086 & 0.5823 & -0.0248 & 0.019 & -0.0267 & -0.0291 & -0.0023 & 0.0137 & -0.1252 & 0.5671 \\
\hline Stomach Ache & 0.0118 & 0.0303 & -0.0146 & -0.062 & -0.0198 & 0.6003 & 0.1256 & -0.0495 & 0.1879 & 0.5291 \\
\hline Vomiting & -0.001 & -0.014 & -0.0032 & 0.0092 & -0.0336 & -0.0022 & 0.6768 & 0.0056 & -0.0059 & 0.5407 \\
\hline $\begin{array}{l}\text { Lower Respiratory } \\
\text { (Chest, Lungs) }\end{array}$ & 0.0174 & 0.1007 & 0.0167 & -0.0549 & -0.0151 & -0.081 & -0.0288 & 0.4814 & 0.1093 & 0.3187 \\
\hline Flu & 0.0268 & 0.3315 & -0.0371 & -0.0954 & 0.0163 & -0.214 & -0.0562 & -0.154 & 0.1983 & 0.2889 \\
\hline Asthma & -0.0046 & 0.0012 & 0.7063 & -0.0268 & -0.0132 & -0.0128 & -0.0057 & -0.0272 & -0.0003 & 0.6827 \\
\hline Backache & 0.0566 & -0.022 & 0.0241 & -0.0037 & 0.0092 & 0.0807 & -0.043 & 0.087 & 0.4104 & 0.217 \\
\hline Heart Problem & 0.0094 & 0.007 & -0.0086 & -0.0517 & 0.3125 & -0.0442 & -0.0028 & -0.049 & 0.0787 & 0.1299 \\
\hline
\end{tabular}




\begin{tabular}{|c|c|c|c|c|c|c|c|c|c|c|}
\hline Blood Pressure & 0.0347 & -0.0135 & -0.0021 & -0.0694 & 0.6067 & -0.0702 & 0.014 & 0.0189 & 0.0677 & 0.4625 \\
\hline Diabetes & 0.015 & -0.0259 & -0.0141 & -0.0402 & 0.5738 & -0.0293 & -0.0094 & -0.0214 & -0.0171 & 0.3996 \\
\hline Mental Disorder & -0.1124 & 0.0126 & -0.0004 & 0.5339 & -0.0556 & -0.1052 & 0.0053 & -0.1213 & 0.0863 & 0.3707 \\
\hline $\begin{array}{l}\text { Sexually Transmitted } \\
\text { Disease }\end{array}$ & -0.0169 & -0.0037 & -0.0032 & -0.0151 & 0.1659 & 0.1123 & -0.0375 & -0.0357 & -0.0366 & 0.0521 \\
\hline Fracture & -0.025 & 0.0631 & -0.0064 & 0.2673 & -0.0189 & -0.0042 & -0.0121 & -0.0311 & -0.0966 & 0.102 \\
\hline $\begin{array}{l}\text { Unspecified Long- } \\
\text { Term Illness }\end{array}$ & 0.0513 & -0.0337 & 0.0044 & 0.2651 & -0.0314 & 0.0685 & -0.0217 & 0.0451 & -0.0013 & 0.1099 \\
\hline HIVAIDS & 0.1137 & 0.0356 & 0.0357 & -0.0801 & -0.0304 & 0.0409 & -0.0491 & -0.0251 & -0.0013 & 0.0359 \\
\hline Typhoid & 0.0169 & 0.2921 & -0.0134 & 0.0086 & -0.0719 & 0.115 & -0.1268 & -0.0338 & -0.4716 & 0.3811 \\
\hline Cancer & 0.009 & 0.0106 & -0.0171 & 0.104 & -0.0015 & 0.0959 & -0.0737 & 0.0425 & -0.0861 & 0.0409 \\
\hline Arthritis/Rheumatism & 0.0256 & -0.0072 & 0.6987 & 0.0099 & -0.0016 & -0.0063 & 0.0038 & 0.0147 & 0.0088 & 0.6754 \\
\hline Nerve Disorder & -0.0704 & -0.0658 & -0.001 & 0.4006 & -0.0478 & -0.0568 & 0.0408 & 0.0557 & 0.2519 & 0.2707 \\
\hline Stomach Disorder & 0.0226 & -0.0482 & -0.0043 & 0.0138 & -0.0039 & 0.6565 & -0.0832 & -0.064 & -0.02 & 0.513 \\
\hline Pneumonia & -0.0353 & -0.0767 & -0.0347 & 0.0374 & -0.0184 & 0.0043 & -0.0141 & 0.6956 & -0.0244 & 0.5365 \\
\hline $\begin{array}{l}\text { No of times } \\
\text { consulted a health } \\
\text { provider }\end{array}$ & 0.0073 & 0.6300 & 0.0448 & 0.0257 & 0.0312 & 0.0713 & 0.0769 & 0.0945 & 0.1324 & 0.8152 \\
\hline $\begin{array}{l}\text { Sweep floor with } \\
\text { difficulty or not at all } \\
\text { able }\end{array}$ & 0.6753 & -0.0095 & -0.0108 & 0.049 & 0.0072 & -0.0142 & 0.016 & 0.02 & -0.0029 & 0.8574 \\
\hline $\begin{array}{l}\text { Walk for } 2 \mathrm{~km} \text { flat } \\
\text { path with difficulty } \\
\text { or not at all able }\end{array}$ & 0.6757 & -0.0033 & -0.0086 & 0.0498 & 0.0147 & -0.0097 & 0.018 & 0.0152 & -0.0055 & 0.8619 \\
\hline $\begin{array}{l}\text { Sought preventive } \\
\text { services from health } \\
\text { provider }\end{array}$ & -0.0978 & 0.0396 & 0.022 & 0.2051 & 0.3074 & 0.0897 & 0.0709 & 0.0316 & -0.0882 & 0.212 \\
\hline $\begin{array}{l}\text { Hospitalized in the } \\
\text { past } 12 \text { months ago }\end{array}$ & -0.0649 & 0.0775 & 0.0567 & 0.3191 & 0.249 & 0.199 & -0.0512 & 0.1731 & -0.1868 & 0.3652 \\
\hline $\begin{array}{l}\text { Physically } \\
\text { handicapped }\end{array}$ & 0.1645 & -0.0211 & -0.0152 & 0.4569 & -0.0074 & -0.0391 & 0.0176 & -0.0781 & 0.0244 & 0.3568 \\
\hline $\begin{array}{l}\text { Variance (total } \\
\text { 11.95) }\end{array}$ & & & & & & & & & & 11.95 \\
\hline $\begin{array}{l}\% \text { of total variance } \\
\text { explained ALL } 31 \\
\text { factors }=\mathbf{3 8 . 5 3} \%\end{array}$ & & & & & & & & & & 38.53 \\
\hline
\end{tabular}

Table 1 shows the results of the principal components analysis (PCA) for the health conditions and sought medical services. The overall KMO measure of sampling adequacy of 0.5148 and it fell within the recommended bare minimum value of .5 (see Field, 2009). This was an indication that there was a linear relationship between the 31 variables and that it was appropriate to run a principal component analysis. In order to establish the umbrella term used to summarize a set of variables that loads highly on a specific factor, the highest loadings greater than 0.25 ( 0.3 to the nearest one decimal place) were selected and highlighted. The first component (comp1) loads on sweep floor or walk for $2 \mathrm{~km}$ flat path with difficulty or not at all able represents physical disability in individuals. The second component (comp2) represents health conditions which make individuals to frequently consult health providers, and they include chronic malaria/fever and flu. The third component (comp3) is associated with asthma and arthritis/rheumatism. The fourth component (comp4) represents health conditions which causes both physical disability and hospitalization in the past 12 months ago among individuals. Based on the computed principal components they are mental disorder, nerve disorder, fracture, and unspecified long term illness. The fifth component (comp5) is interpreted to represent health conditions which make individuals to seek preventive services from health providers; they are heart problem, blood pressure, and diabetes, all of which are noncommunicable diseases (NCDs). The sixth component (comp6) represents stomach ache, and stomach disorder. The seventh component (comp7) was interpreted as diarrhea and vomiting. The eighth component (comp8) loads highly on upper respiratory (Sinuses), lower respiratory (chest, lungs) and pneumonia; while the ninth component (comp9) loads on typhoid and dental problem and their associated signs like backache and headache.

Certain components especially comp2, comp4 and comp5 are very crucial as they are directly linked with demand for medical services such as frequenting health providers for consultation, hospitalization, Physical disability and preventive care. Even though individuals frequent health providers due to health conditions represented in comp2 
such as chronic malaria/fever and flu it will not be the focus for this study. Moreover, although individuals demand preventive care mainly due to non-communicable diseases represented in comp5 such as heart problem, blood pressure, and diabetes, the same will not be the focus for this study. This was the case since Muthama (2018b) in his study already unveiled the effect of both household response to shocks and diet on chronic non communicable illnesses. The health conditions which cause physical disability and hospitalization among individuals (comp4) such as mental disorder, nerve disorder, unspecified long term illness, and fracture will be the focus for this study. A decline in fractures signifies an improvement in bone health for this study. This is because broken bones (called fractures) can be painful and sometimes need surgery to heal hence hospitalization and they can also cause longlasting health problems. Healthy bones are a sign of good health, but unhealthy bones are a sign of poor health, since bones are in one sense the manufactures of the blood which is the life of the body, "for the life of the flesh is in the blood" as written in Leviticus 17:11 in The Holy Book (1982d).

\subsection{Principal Component Analysis for Shocks and Response to the Shocks}

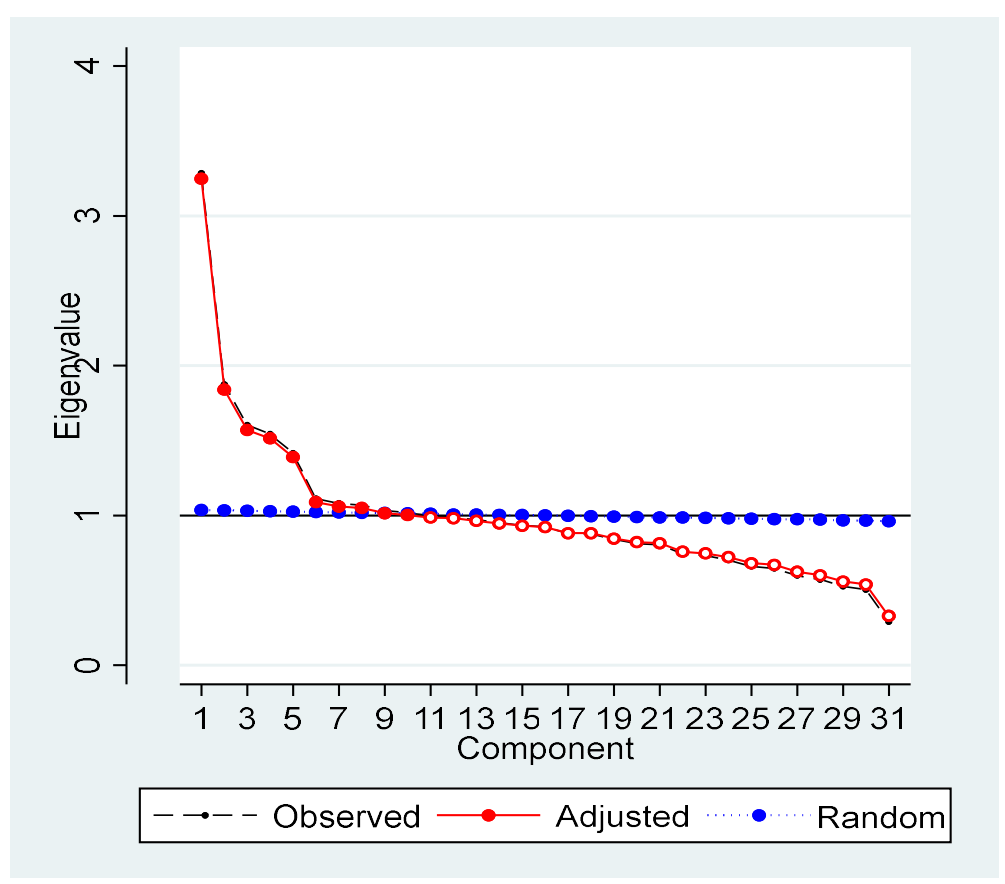

Figure 2: Horn's parallel analysis for Shocks and Response to the Shocks

After extracting all the principal components, the Horn's parallel analysis was used to determine the number of components to retain for rotation and interpretation as illustrated in figure 2 . The components were rotated using a Varimax (Kaiser) rotation. This criterion produced eight components and was included on the grounds that they represent important aspects of the various shocks and ways of response to the shocks and could conveniently be interpreted. The highest loadings on each component were highlighted and the interpretation of component is based on them. For the various shocks and the ways of response to the shocks, the eight factors conveyed $41.89 \%$ of the total variation of the set of 31 original variables.

Table 2: Principal Component Analysis for Shocks and Response to the Shocks

\begin{tabular}{|c|c|c|c|c|c|c|c|c|c|}
\hline Variable & $\begin{array}{r}\text { Comp } \\
1\end{array}$ & $\begin{array}{r}\text { Comp } \\
2\end{array}$ & $\begin{array}{r}\text { Comp } \\
3\end{array}$ & $\begin{array}{r}\text { Comp } \\
4\end{array}$ & $\begin{array}{r}\text { Comp } \\
5\end{array}$ & $\begin{array}{r}\text { Comp } \\
6 \\
\end{array}$ & $\begin{array}{r}\text { Comp } \\
7\end{array}$ & $\begin{array}{r}\text { Comp } \\
8\end{array}$ & $\begin{array}{r}\text { Explain } \\
\text { ed }\end{array}$ \\
\hline Severe water shortage Drought or Floods & 0.065 & 0.4754 & 0.03 & 0.0713 & 0.0126 & 0.0717 & $\begin{array}{r}- \\
0.0266 \\
\end{array}$ & 0.0153 & 0.516 \\
\hline $\begin{array}{l}\text { Death of } \mathrm{HH} \text { head, working member of } \\
\text { household, or other family member }\end{array}$ & 0.001 & $0.1146^{-}$ & 0.0945 & 0.6032 & 0.0466 & 0.0409 & $\begin{array}{r}- \\
0.0017 \\
\end{array}$ & 0.0297 & 0.6386 \\
\hline $\begin{array}{l}\text { Asset /Dwelling damaged, destroyed by } \\
\text { Fire, Carjacking/Robbery/burglary/assault }\end{array}$ & 0.0959 & 0.013 & 0.1235 & 0.1005 & 0.0597 & 0.2079 & 0.0037 & $\begin{array}{r}- \\
0.0098 \\
\end{array}$ & 0.1331 \\
\hline Crop disease or crop pests & $\begin{array}{r}- \\
0.0187 \\
\end{array}$ & 0.0878 & 0.0999 & $\begin{array}{r}- \\
0.0285 \\
\end{array}$ & 0.2019 & 0.2167 & $0.1177^{-}$ & 0.0206 & 0.1661 \\
\hline Livestock died or were stolen & 0.0442 & 0.3711 & 0.0788 & 0.002 & 0.062 & 0.0104 & 0.0117 & 0.0359 & 0.2963 \\
\hline
\end{tabular}




\begin{tabular}{|c|c|c|c|c|c|c|c|c|c|}
\hline $\begin{array}{llll}\begin{array}{l}\text { Household } \\
\text { agricultural }\end{array} & \text { business } & \text { failure, } & \text { non- } \\
\end{array}$ & 0.0185 & 0.0735 & 0.0137 & 0.0018 & 0.0773 & 0.6001 & 0.0017 & -0.051 & 0.5072 \\
\hline $\begin{array}{l}\text { Loss of salaried employment or non- } \\
\text { payment of salary }\end{array}$ & 0.0295 & 0.0549 & 0.0374 & 0.0246 & 0.0384 & 0.0715 & 0.6698 & 0.0563 & 0.6138 \\
\hline $\begin{array}{l}\text { End of regular assistance, aid, or } \\
\text { remittances from outside HH }\end{array}$ & 0.1045 & 0.0332 & 0.0414 & 0.0421 & $\begin{array}{r}- \\
0.0691 \\
\end{array}$ & 0.0517 & 0.0119 & 0.3747 & 0.2045 \\
\hline Large fall in sale prices for crops & 0.0062 & -0.013 & 0.0764 & 0.0331 & 0.5672 & 0.0162 & 0.0098 & 0.0554 & 0.5023 \\
\hline Large rise in price of food & 0.4459 & 0.0128 & $\begin{array}{r}- \\
0.0074\end{array}$ & 0.0162 & 0.1474 & 0.0243 & 0.0293 & $\begin{array}{r}- \\
0.0667\end{array}$ & 0.5399 \\
\hline Large rise in agricultural input prices & 0.0585 & 0. & $\begin{array}{r}- \\
0.0305 \\
\end{array}$ & 0. & $\mathbf{0 . 5 5 3 7}$ & $0.041 \overline{1}^{-}$ & 0.0135 & $\begin{array}{r}- \\
0.0585 \\
\end{array}$ & 0.4976 \\
\hline $\begin{array}{l}\text { Chronic/severe illness or accident of } \\
\text { household member }\end{array}$ & 0.0823 & 0.0058 & 0.5389 & 0.0912 & 0.0167 & 0. & $0.0032^{-}$ & $\begin{array}{r}- \\
0.0196 \\
\end{array}$ & 0.504 \\
\hline Birth in the household & 0.1632 & 0.0807 & 0.3598 & 0.2791 & 0.1758 & 0.0815 & 0.1568 & 0.0589 & 0.3444 \\
\hline Break-up of the household & 0.0674 & 0.0452 & $0.1313^{-}$ & 0.0744 & 0.0336 & 0.1114 & 0.0125 & 0.5627 & 0.4022 \\
\hline Jailed & $0.0412^{-}$ & 0.0576 & 0.2024 & 0.0523 & 0.0461 & 0.0472 & $0.138 \overline{1}^{-}$ & 0.2585 & 0.167 \\
\hline HIV/AIDS & 0.0055 & $\begin{array}{r}- \\
0.0233\end{array}$ & $0.1172^{-}$ & 0.2316 & 0.0228 & 0.1119 & $\begin{array}{r}- \\
0.0925\end{array}$ & 0.0463 & 0.1104 \\
\hline Spent cash saving & 0.0197 & 0.0068 & 0.2684 & 0.1119 & 0.2931 & 0.0819 & 0.0761 & 0.1241 & 0.3959 \\
\hline $\begin{array}{l}\text { Removed children from school to work/ } \\
\text { Sent children to live with relatives }\end{array}$ & 0.018 & 0.0564 & -0.028 & $\begin{array}{r}- \\
0.0046 \\
\end{array}$ & 0.031 & 0.0387 & 0.0507 & 0.5983 & 0.4362 \\
\hline $\begin{array}{l}\text { Sold farm land, animals, more crops, assets } \\
\text { like (tools, furniture etc), }\end{array}$ & 0.0558 & 0.2699 & 0.3265 & $0.0132^{-}$ & 0.2058 & $0.0036^{-}$ & $0.0282^{-}$ & 0.0982 & 0.4617 \\
\hline Rented out farm land & $\begin{array}{r}- \\
0.0537 \\
\end{array}$ & 0.0074 & 0.0571 & 0.04 & 0.2589 & -0.073 & 0.0119 & 0.1649 & 0.1506 \\
\hline $\begin{array}{l}\text { Other household members who weren't } \\
\text { working went to work/ Worked more, } \\
\text { worked longer hours }\end{array}$ & 0.0799 & 0.0862 & 0.1042 & 0.0562 & 0.1544 & 0.3463 & $0.081 \overline{6}$ & 0.1335 & 0.3595 \\
\hline Started a new business & 0.0324 & 0.0028 & 0.0598 & 0.0307 & $0.0414^{-}$ & 0.5934 & 0.1042 & 0.0247 & 0.5214 \\
\hline $\begin{array}{l}\text { Went elsewhere to find work for more than } \\
\text { a month }\end{array}$ & 0.0091 & 0.0546 & 0.0071 & 0.0463 & 0.0269 & 0.0478 & 0.6683 & 0.0752 & 0.5745 \\
\hline $\begin{array}{l}\text { Borrowed money from relatives, money } \\
\text { lender, institutions (banks etc) }\end{array}$ & 0.0294 & 0.0283 & 0.4198 & $\begin{array}{r}- \\
0.0445\end{array}$ & 0.0137 & 0.0398 & 0.0641 & 0.0019 & 0.3002 \\
\hline $\begin{array}{lccc}\text { Received help from local or/and } \\
\text { international NGO }\end{array}$ & 0.0108 & 0.4690 & 0.1327 & 0.0569 & 0.0825 & 0.0389 & 0.0186 & 0.0651 & 0.461 \\
\hline Received help from Government & 0.0018 & 0.5161 & -0.044 & 0.0171 & 0.0882 & 0.0015 & 0.0051 & 0.0733 & 0.5257 \\
\hline $\begin{array}{l}\text { Spiritual help from religious institutions } \\
\text { including prayers, sacrifices, or consulted } \\
\text { diviner }\end{array}$ & 0.067 & 0.0553 & 0.0939 & 0.5488 & -0.036 & 0.0142 & -0.034 & 0.007 & 0.5098 \\
\hline Received help from family/friends & 0.031 & 0.0681 & 0.2325 & 0.3695 & -0.092 & 0.0015 & 0.0488 & 0.0568 & 0.4525 \\
\hline Reduced food consumption & 0.4726 & 0.0662 & 0.0263 & 0.0042 & 0.0486 & 0.0254 & 0.0226 & 0.0356 & 0.5619 \\
\hline $\begin{array}{l}\text { Consumed lower cost, but less preferred } \\
\text { foods }\end{array}$ & 0.4951 & 0.0247 & 0.0061 & 0.044 & 0.0527 & 0.0107 & 0.0139 & 0.0434 & 0.5774 \\
\hline Reduced non-food expenditures & 0.4909 & 0.0413 & 0.0151 & 0.0039 & 0.0065 & 0.0138 & 0.0289 & 0.0187 & 0.5543 \\
\hline Variance (total 12.99) & & & & & & & & & 12.99 \\
\hline $\begin{array}{l}\% \text { of total variance explained ALL } 31 \\
\text { factors }=\mathbf{4 1 . 8 9} \%\end{array}$ & & & & & & & & & 41.89 \\
\hline
\end{tabular}

Table 2 shows the results of the principal component analysis for the shocks and ways of response to the shocks. The overall KMO measure of sampling adequacy of 0.6343 and it fell within the recommended minimum value of .5. This was an indication that there was a linear relationship between the 31 variables and that it was appropriate to run a principal component analysis. In order to establish the umbrella term used to summarize a set of variables that loads highly on a specific factor, the highest loadings greater than 0.30 were selected and highlighted. The first component (comp1) represents a shock in large rise in price of food and the response to shocks was through consuming lower cost but less preferred foods, reducing food consumption, and reducing non-food expenditures. The second component (comp2) represents shock of severe water shortage/ drought or floods which leads to reduction in livestock as some died and/or stolen. The response to shock was done through receiving help from government, and local or/and international NGO. The third component (comp3) represents shock of chronic/severe 
illness or accident of household member and birth in the household; and the response to shock was through selling farm land, animals, more crops, and other assets like tools and/or furniture and borrowing money from relatives, money lenders or institutions like banks. The fourth component (comp4) represents death shock (either for household head, working member of household, or other family member); the response to shock is mainly through seeking spiritual help from religious institutions including prayers, sacrifices, or consulted diviner; and receiving help from family/friends. The fifth component (comp5) represents two types of interrelated shocks namely large rise in agricultural input prices and large fall in sale prices for crops. The sixth component (comp6) represents nonagricultural household business failure; and the response to shocks was done through starting a new business; and ensuring other household members who weren't working went to work/ worked more, or even worked longer hours. The seventh component (comp7) represents shock due to loss of salaried employment or non-payment of salary; and the response is by going elsewhere to find work for more than a month. The eighth component (comp8) represents shock of break-up of the household and end of regular assistance, aid, or remittances from outside household; and the response to shocks was removing children from school to work/ sending children to live with relatives.

Based on the shocks and response to the shocks, two main groupings can be deduced. The first group consists of the bad reports and the second group comprises the good reports to the individuals. The bad reports which are deemed to worsen individuals/ households' welfare consists of all the shocks and the negative response to the shocks; while the good reports which improves individuals/ households' welfare consist of the positive response to the shocks. The specific shocks for the bad reports are chronic/severe illness or accident of household member; loss of salaried employment or non-payment of salary; non-agricultural household business failure; severe water shortage/ drought or floods; death (either for household head, working member of household, or other family member); and going elsewhere to find work for more than a month. Response to shocks which can be regarded as good reports include receiving help from government; local or/and international NGO; selling farm land, animals, more crops, assets like (tools, furniture); seeking spiritual help including prayers, sacrifices, or consulting diviner; and starting a new business.

\subsection{Principal Component Analysis for Food and Nutrition}

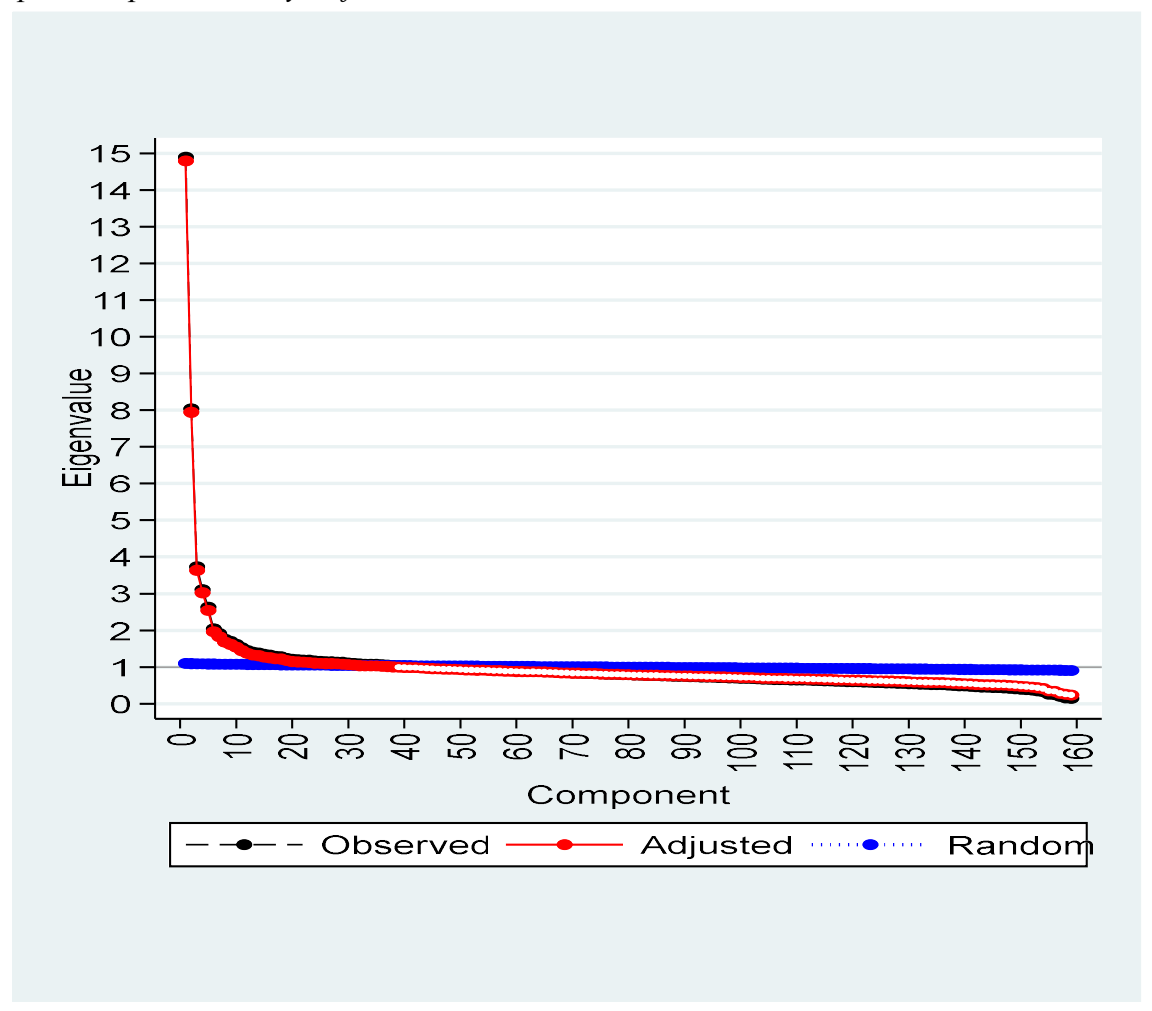

Figure 3: Horn's parallel analysis for Food and Nutrition

After extracting all the principal components, the Horn's parallel analysis was used to determine the number of 
components to retain for rotation and interpretation as illustrated in figure 3 . The components were rotated using a Varimax (Kaiser) rotation. This criterion produced 31 components and was included on the grounds that they represent important aspects of the various food and nutrition and could conveniently be interpreted. The highest loadings on each component were highlighted and the interpretation of component is based on them. For food and nutrition, the 31 factors conveyed $42.51 \%$ of the total variation of the set of 159 original variables.

The table showing the results of the 159 original variables and their corresponding 31 principal components for food and nutrition was bulky to fit in the text and hence was left in a separate excel file, which can be availed upon request. The overall KMO measure of sampling adequacy of 0.9508 and it fell within the recommended minimum value of .5. This was an indication that there was a linear relationship between the 159 variables and that it was appropriate to run a principal component analysis. In order to establish the umbrella term used to summarize a set of variables that loads highly on a specific factor, the highest loadings greater than 0.25 (0.3 to the nearest one decimal place) were selected and highlighted. The first component (comp1) represents ingredients for preparing tea (tea leaves, sugar only, milk), fried githeri (maize grain loose, beans, salt, onion leeks, cooking fat), and ugali (maize flour). The second component (comp2) represents bread and soda. The third component (comp3) is associated with pilipili hoho, dania, spinach, rice, and melons. The fourth component (comp4) represents grapes, mustard, cauliflower, cheese, and lettuce. The fifth component (comp5) is interpreted to represent chili sauce, tomato sauce, peanut butter, jam. The sixth component (comp6) represents dried/smoked fish, maize flour loose, other vegetables, groundnuts, sweet potato. The seventh component (comp7) is ham salami, minced meat, beef without bones, bacon. The eighth component (comp8) is labelled as cooking banana, arrow roots, yams, squashes, pumpkins. The ninth component (comp9) was interpreted as vegetables (courgette, and celery), vinegar, and wine; while the tenth component (comp10) was interpreted as camel meat, cooking oil, pasta (spaghetti/macaroni). Component 11 represents food from vendors, milk fresh packet, fresh fish, and coconut. Component 12 represents sweets, chewing gum, biscuits. Component 13 is associated with sorghum grain, cassava flour, sorghum flour, millet grain wimbi, cassava. Component 14 represents vegetables (okra, biringanya, and cucumber), and coconut. Component 15 is interpreted to represent other pulses, drinking chocó, chocolate, teabags. Component 16 represents cowpea, other millet grain flour, peas, and grams. Component 17 represents tinned vegetables and pulses as it composed of vegetables tined and pulses tinned. Component 18 is labelled as alcoholic beverage (cider), and ingredients for making dough (baking powder, and yeast). Component 19 was interpreted as drugs and substance abuse (spirits, beer, and cigarettes); while component 20 was interpreted as fruits (peaches), corned beef, and pickles. Component 21 represents milk fresh flavored, lard, other berries, and preserved fruit. Component 22 represents traditional drugs and substances as composed of snuff and traditional brew. Component 23 is associated with fresh cream, marmalade, and mala. Component 24 represents miraa, tobacco processed, and grounded coffee. Component 25 is interpreted to represent tinned meat and beans (meat tinned, and beans tinned). Component 26 represents plums, and frozen fish fillets. Component 27 is UHT fresh flavored and other sugars. Component 28 is labelled as barley and other cereals, and milk powder. Component 29 was interpreted as baby milk, cereals tinned, and ghee from milk; component 30 was interpreted as sugar icing, and fish tinned; while component 31 represents other meats, sugarcane, pears, cigars, and soya drink.

\section{Study Findings and Discussion of Results}

\subsection{Regression Model on Production of Bone Health}

In this study bone health is measured by fracture and hence as the bone fractures decrease it connotes improvement in bone health. However, an increase in the bone fractures denotes deterioration in bone health.

Table 3: Regression Results on Production of Bone health

\begin{tabular}{|l|r|r|r|r|r|r|}
\hline & \multicolumn{3}{|c|}{ Model I } & \multicolumn{3}{c|}{ Model II } \\
\hline Bad reports & Coefficient & t-statistic & P-value & Coefficient & t-statistic & P-value \\
\hline Chronic illness & $\mathbf{0 . 0 0 0 5}$ & $\mathbf{1 . 9 7 * *}$ & $\mathbf{0 . 0 5 1}$ & & & \\
\hline $\begin{array}{l}\text { Separation (death, finding work for more than a } \\
\text { month, break up, and sending children to live with } \\
\text { relatives) }\end{array}$ & & & & $0.0016^{* *}$ & & 1.91 \\
\hline $\begin{array}{l}\text { Reduced Income (household business failure and } \\
\text { loss of employment) }\end{array}$ & & & & 0.0003 & 0.058 & 0.503 \\
\hline $\begin{array}{l}\text { Increase in Cost of production (large fall in crop } \\
\text { prices, large rise in agricultural inputs, water } \\
\text { shortage and drought }\end{array}$ & & & & 0.0002 & 0.18 & 0.861 \\
\hline
\end{tabular}




\begin{tabular}{|c|c|c|c|c|c|c|}
\hline $\begin{array}{l}\text { Reduced Consumption (reduced food consumption, } \\
\text { non-food expenditure, consuming lower cost foods) }\end{array}$ & & & & 0.0001 & 0.43 & 0.67 \\
\hline Good reports & -0.0008 & $-1.68 * *$ & 0.096 & & & \\
\hline Receiving help from local or/and international NGO & & & & -0.0009 & -0.74 & 0.462 \\
\hline Receiving help from government & & & & -0.0009 & -1.01 & 0.316 \\
\hline Seeking spiritual help & & & & -0.0009 & -1.15 & 0.252 \\
\hline Increase in disposable income (borrowing money) & & & & -0.0004 & -0.36 & 0.719 \\
\hline Starting a new business & & & & $-0.0017 * *$ & -1.95 & 0.053 \\
\hline Sex (Female 0 Male 1$)$ & 0.0008 & 1.19 & 0.237 & 0.0007 & 1.16 & 0.247 \\
\hline Residence (Urban 0 rural 1) & -0.0003 & -0.32 & 0.746 & -0.0005 & -0.62 & 0.536 \\
\hline Age & $0.0001^{*}$ & 4.16 & 0.000 & $0.0001 *$ & 4.08 & 0.000 \\
\hline Completed Secondary Education & $-0.0010^{* *}$ & -1.67 & 0.096 & -0.0010 & -1.65 & 0.101 \\
\hline Exercise (motorized transport 0 non-motorized 1 ) & $-0.0017 * *$ & -1.79 & 0.075 & $-0.0017 * *$ & -1.76 & 0.081 \\
\hline Tea with milk & -0.0008 & -1.06 & 0.291 & -0.0008 & -1.08 & 0.280 \\
\hline Fried githeri & -0.0005 & -1.44 & 0.153 & -0.0005 & -1.61 & 0.109 \\
\hline Bread & $0.0021^{*}$ & 2.43 & 0.016 & $0.0021^{*}$ & 2.51 & 0.013 \\
\hline Sodas & 0.0002 & 0.26 & 0.797 & 0.0002 & 0.23 & 0.821 \\
\hline Fresh fish & -0.0001 & -0.11 & 0.915 & -0.0001 & -0.07 & 0.943 \\
\hline Dried/smoked fish & 0.0008 & 1.00 & 0.317 & 0.0008 & 1.09 & 0.278 \\
\hline Frozen Fish Filets & 0.0092 & 1.44 & 0.152 & 0.0092 & 1.45 & 0.148 \\
\hline Fish tinned & $-0.0040^{*}$ & -2.08 & 0.039 & $-0.0042 *$ & -2.18 & 0.031 \\
\hline Rice Grade 2 & -0.0007 & -1.27 & 0.208 & -0.0006 & -1.11 & 0.271 \\
\hline Maize Flour Loose & -0.0001 & -0.17 & 0.869 & -0.0001 & -0.20 & 0.841 \\
\hline Other vegetables & 0.0002 & 0.29 & 0.769 & 0.0001 & 0.21 & 0.833 \\
\hline Minced meat & $-0.0032 *$ & -2.53 & 0.012 & $-0.0031 *$ & -2.51 & 0.013 \\
\hline Bacon & -0.0010 & -0.58 & 0.561 & -0.0012 & -0.73 & 0.466 \\
\hline Corned beef & $0.0103 *$ & 2.4 & 0.017 & $0.0092 *$ & 2.10 & 0.037 \\
\hline Pasta (spaghetti/macaroni) & 0.0013 & 0.53 & 0.600 & 0.0013 & 0.55 & 0.585 \\
\hline Cassava flour & -0.0011 & -1.1 & 0.275 & -0.0010 & -1.02 & 0.307 \\
\hline Millet grain wimbi & -0.0008 & -1.14 & 0.258 & -0.0009 & -1.25 & 0.212 \\
\hline Cereals milk & 0.0069 & 1.56 & 0.121 & 0.0069 & 1.56 & 0.121 \\
\hline Peas & -0.0005 & -0.57 & 0.571 & -0.0004 & -0.50 & 0.616 \\
\hline Grams & -0.0003 & -0.32 & 0.749 & -0.0003 & -0.34 & 0.737 \\
\hline Yoghurt & 0.0000 & -0.02 & 0.986 & -0.0001 & -0.03 & 0.978 \\
\hline Flavored milk and lard & 0.0015 & 0.92 & 0.360 & 0.0015 & 0.92 & 0.359 \\
\hline Cauliflower & -0.0017 & -1.24 & 0.216 & -0.0016 & -1.22 & 0.224 \\
\hline Pineapples & $-0.0019^{*}$ & -3.50 & 0.001 & $-0.0020^{*}$ & -3.62 & 0.000 \\
\hline Melons & $-0.0024 *$ & -2.29 & 0.023 & $-0.0024 *$ & -2.29 & 0.023 \\
\hline Apples & $-0.0012 * *$ & -1.70 & 0.092 & $-0.0012 * *$ & -1.67 & 0.097 \\
\hline Passions & -0.0010 & -1.06 & 0.289 & -0.0010 & -1.08 & 0.280 \\
\hline Ripe Banana & -0.0002 & -0.32 & 0.746 & -0.0002 & -0.33 & 0.745 \\
\hline Peanut butter & $-0.0039^{*}$ & -2.37 & 0.019 & $-0.0040 *$ & -2.41 & 0.017 \\
\hline Marmalade & -0.0014 & -0.95 & 0.345 & -0.0012 & -0.81 & 0.418 \\
\hline Margarine & -0.0017 & -1.40 & 0.162 & -0.0016 & -1.36 & 0.174 \\
\hline
\end{tabular}




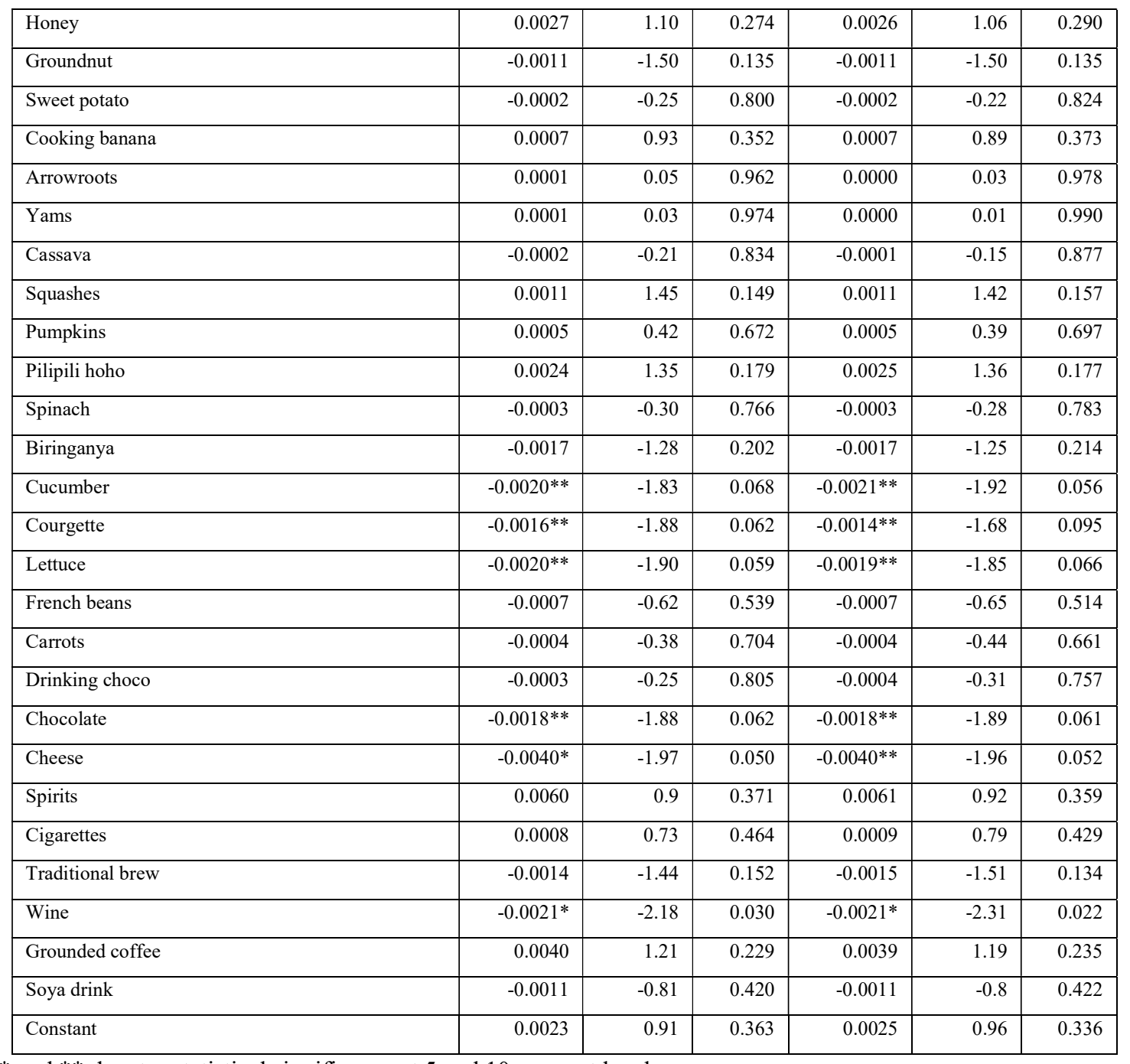

* and ** denotes statistical significance at 5 and 10 per cent level

The regression results in Table 3 model I gave a coefficient for bad reports of 0.0005 with an associated p-value of 0.051 which is statistically significant. In addition model II finds a coefficient for chronic/severe illness or accident of household member of 0.0016 (p-value 0.058 ) which is statistically significant. Likewise increase in the cost of production had a coefficient of 0.0011 ( $\mathrm{p}$-value 0.015 ) which is statistically significant. This indicates that bad reports especially chronic/severe illness or accident of household member and increase in the cost of production has an adverse effect on bone health by making the health to deteriorate. This finding is in support of what was manifested in the life of a man as recorded in Job 4:14 in The Holy Book (1982c) who was living in full health until he got disturbing news about loss of family members (his children) and loss of income when his livestock died out of a natural calamity. The body responded by fever (trembling) and all his bones were shaking as a result of the bad report.

Conversely model I gave a coefficient for good reports of -0.0008 with an associated p-value of 0.096 which is less than the critical p-value of 0.10 (10 per cent) indicating that the variable is statistically different from zero, and hence statistically significant. The fact that the coefficient is negative and statistically significant indicates that the presence of good reports leads to an improvement in bone health, a finding which is in line with Proverbs 15:30 in The Holy Book (1982e) that a good report makes the bones healthy. Moreover, model II produced a coefficient for starting a new business of -0.0017 ( $\mathrm{p}$-value 0.053 ) which is statistically significant. Although response to shocks by receiving help from local or/and international NGO, receiving help from government, seeking spiritual help, and increase in disposable income through borrowing money from relatives, money lenders, and institutions each had negative coefficient value $(-0.0009,-0.0009,-0.0009$ and -0.0004$)$ the associated p-values of $0.316,0.462$, 0.252 and 0.719 respectively exceeded the 0.05 and even 0.10 level of significance. Hence they were not 
statistically significant in explaining bone health. This implies that although responding to shock of severe water shortage/ drought or floods through receiving help from government, and local or/and international NGO is right, the same does not help in improvement of bone health. Similarly, responding to death shock through seeking spiritual help from religious institutions including prayers, sacrifices, or consulting diviner does not significantly help in bone health improvement. Moreover, for improved bone health, the response to shock of non-agricultural household business failure should be through starting a new business. Lastly, for improvement in bone health, individuals ought not to respond to shock of chronic/severe illness or accident of household member through borrowing money from relatives, money lenders, and institutions.

Model I produced a negative and statistically significant coefficient for completing secondary education of -0.0010 (p-value 0.096) which is statistically significant at 10 per cent level of significance. This shows that individuals who have attained and completed their secondary level of education have significantly less fractures and thus have improved bone health compared to their counterparts who have not completed secondary education. The reason for the observed findings could be as deduced by De Jonge (2016) that higher education was associated with better dietary quality at baseline, and with more improvement of dietary quality over time. A positive coefficient of 0.0001 (p-value 0.000 ) for both model I and model II which is statistically significant for age, shows that the chances of bone fracture increases with the age in years of an individual. Thus, the older an individual is, the more likely he/she will have bone fracture, implying that individuals bone health deteriorates with increase in age. However, a coefficient for exercise of -0.0017 with an associated p-value of 0.075 for model I and 0.081 for model II indicates that the variable is statistically different from zero, and hence statistically significant. The fact that the coefficient is negative and statistically significant shows that exercising (through use of non-motorized transport) improves bone health. The findings are in line with those by Muthama (2018a) that since cycling positively and significantly improve health status, there is need to encourage cycling by creating lanes for cyclists, in every road. The fact that exercising improves bone health and increase in age deteriorates bone health, is related to the idea posed by Troy et al. (2018) that exercise and physical activity during growth lead to increases in bone size, density, and strength that persist for many years. The converse is also implied that failure to exercise leads to reduction in bone size, density, and strength, which may result in increased rate of bone fracture occurrence as an individual advances in age. This concurs with Kruger and Wolber (2016) who observed that osteoporosis is a disease that manifests in the elderly as the elderly population increases, so too will the incidence and prevalence of osteoporosis.

Model I and model II produced a coefficient for bread of 0.0021 (p-value 0.016) and 0.0021 (p-value 0.013) respectively, which are less than 5 per cent. This implies that taking bread has a statistically significant effect on fracture as it increases their chances of occurrence; thus increased bread consumption depletes bone health. The coefficients in Model I for fruits in particular apples have a negative and statistically significant coefficient of 0.0012 ( $\mathrm{p}$-value 0.092) indicating that eating apples reduces bone fractures, hence improves bone health. Similar to findings by Hyson (2011) and Ben-Nun (2016) that apples and apple products may have beneficial effects on outcomes related to cognitive decline of normal aging, diabetes, weight management, and bone health.

In addition fruits specifically pineapples have a negative and statistically significant coefficient of -0.0019 (p-value 0.001 ) indicating that eating pineapples reduces bone fractures, hence improves bone health. The finding is in line with those by Joy (2010) and Hossain et al. (2015) who observed that pineapples are very rich in manganese mineral which is required for the growth of healthy bones and connective tissues. Hossain et al. (2015) added that several essential minerals exist in pineapples, one of which is manganese, a trace mineral which can affect the growth of bones in young people and the strengthening of bones in older people. Likewise, melon fruits have a negative and statistically significant coefficient of -0.0024 (p-value 0.023 ), indicating that eating melons reduces bone fractures, hence improves bone health.

Vegetables such as lettuce, cucumber and courgette have a negative and statistically significant coefficient of 0.0020 (p-value 0.059), -0.0020 (p-value 0.068) and -0.0016 (p-value 0.062) from model I, clearly showing that taking vegetables specifically lettuce, cucumber and courgette reduces bone fracture, and thus improves bone health. A sufficient intake of vitamin $\mathrm{K}$ has been associated with healthy bones that are less likely to fracture. Lettuce is a good source of Vitamin $\mathrm{K}$ which is required for the correct mineralization of bone. Cucumber contains calcium and also provides a high amount of vitamin $\mathrm{K}$ which has been found to have a potential role in bone strength by promoting osteotrophic (bone mass building) activity (Maheshwari et al., 2014) by improving calcium absorption, hence together, these nutrients contribute to good bone health.

Consumption of peanut butter produced a coefficient of -0.0039 (p-value 0.019 ) and -0.0040 (p-value 0.017 ) in model I and model II respectively, which are less than five per cent. According to Settaluri et al. (2012) peanuts when taken in adequate amounts in any form, will supplement rich nutrients to the body that can provide growth and energy, and play a vital role in the prevention of diseases as they are an excellent and affordable source of 
nutrition, supplementing vital nutrients to the human body such as proteins, carbohydrates, lipids, vitamins, minerals and fiber. Peanuts are a good source of minerals such as magnesium, calcium and phosphorous. Magnesium promotes normal blood pressure, keeps bones strong, and helps to regulate blood sugar levels. Calcium is primarily associated with strengthening of bones, gums and teeth. Phosphorous aids primarily in the formation of bones and teeth along with calcium and helps to synthesize protein for the growth, maintenance and repair of cells, and tissues (Settaluri et al., 2012).

Tinned fish consumption produced a coefficient of -0.0040 (p-value 0.039 ) and -0.0042 (p-value 0.031 ) in model I and model II respectively, which are less than five per cent. In addition, consumption of minced meat produced a coefficient of -0.0032 (p-value 0.012 ) and -0.0031 (p-value 0.013 ) in model I and model II respectively, which are less than five per cent. This shows that increased consumption of peanut butter, tinned fish, and minced meat have a statistically significant effect on bone fracture as it decreases their chances of occurrence; and hence taking peanut butter, tinned fish, and minced meat significantly improves bone health. Consumption of chocolate produced a coefficient of - 0.0018 (p-value 0.062 ) and -0.0018 (p-value 0.061) in model I and model II respectively, which are less than 10 per cent. Moreover, consumption of cheese produced a coefficient of -0.0040 (p-value 0.050 ) and -0.0040 (p-value 0.052) in model I and model II respectively, which are less than 10 per cent, indicating that increased consumption of chocolate and cheese have a statistically significant effect on bone fracture as it decreases their chances of occurrence; and hence taking chocolate and cheese significantly improves bone health. The high concentration of calcium in cheese is well known to contribute to the formation and maintenance of strong bones and teeth; besides calcium other cheese compounds such as magnesium and vitamin D also play an important role in building up bone mineral density and reducing bone loss (Walther et al., 2008).

The consumption of corned beef produced a coefficient of 0.0103 (p-value 0.017) and 0.0092 (p-value 0.037) in model I and model II respectively, which are less than five per cent. Hence, increased consumption of corned beef depletes bone health. The coefficient on individuals who take wine has a negative coefficient of -0.0021 ( $p$-value 0.030 ) for model I and -0.0021 (p-value 0.022 ) for model II both of which are negative and statistically significant at 0.05 level of significance. This shows that taking wine significantly reduces fractures, thus helps improve bone health. This finding is related to the affirmation by 1st Timothy 5:23 The Holy Book (1982b) that it is good to take a little wine because of the stomach and the frequent illnesses, however, don't be drunk with wine Ephesians 5:18 The Holy Book (1982a). Hence, the little wine to be taken ought be unfermented wine since fermented wine is alcohol and excessive alcohol consumption negatively affects the health status of an individual (Muthama, 2018a). Similarly, Passali et al. (2019) established that dietary intake of red wine extract for 6 months significantly prevented bone loss and improved bone strength. Similar findings were deduced by Jang et al. (2017) that mean bone mineral density for light drinkers was statistically significantly greater than that for heavy drinkers and nondrinkers. In the risk factor analysis, the adjusted odds ratio for osteoporosis was 1.68 in non-drinkers and 1.70 in heavy drinkers compared with light drinkers. Hence, in Korea non-drinkers and heavy drinkers had approximately a 1.7-times greater risk for osteoporosis than light drinkers (Jang et al., 2017).

\section{Conclusions and Recommendations}

\subsection{Conclusions}

Bone health is measured by occurrence of fracture in this study; hence as the bone fractures decrease it signifies improvement in bone health. However, an increase in the bone fractures denotes deterioration in bone health. This study establishes that good reports (positive response to shocks) help in improvement of bone health. However, bad reports adversely affect bone health by making the health to deteriorate. This study deduces that exercising improves bone health. We also find that individuals who have attained and completed their secondary level of education have improved bone health compared to their counterparts who have not completed secondary education. The current study also finds that taking wine significantly helps improve bone health.

Intake of fruits in particular apples, pineapples and melons and vegetables such as lettuce, cucumber and courgette improve bone health by reducing bone fractures. In addition, taking peanut butter, tinned fish, and minced meat, chocolate and cheese improved bone health as it reduces fractures; however, increased consumption of bread and corned beef significantly increases the occurrence of fracture as it depletes bone health. The study also shows that bone fracture increases with the individual age hence bone health deteriorates with increase in age.

\subsection{Recommendations}

i). In order to improve individuals' bone health, there is need to convey good reports especially during shocks like Corona virus (Covid-19). 
ii). During the outbreak of corona virus, individuals who have experienced non-agricultural household business failure need not to faint but instead they ought to respond by starting a new business.

iii). For improved bone health, individuals also need to continually exercise especially using non-motorized means of travelling like walking or cycling.

iv). In order to improve bone health, individuals need to take a little wine especially as their age increases, the wine help improve their health by strengthening their bones.

v). $\quad$ For improved bone health, there is need for individuals to increase consumption of apples, pineapples and melons and vegetables such as lettuce, cucumber and courgette in addition to consumption of peanut butter, tinned fish, and minced meat, chocolate and cheese. However, they ought to minimize the consumption of bread and corned beef.

vi). All the above-mentioned measures calls for increased health education on each aspect of the aforementioned factors, coupled with motivation for individuals to attain and complete secondary level of education.

\section{References}

Ben-Nun, Liubov. (2016). Roots/Health Benefits Of Apples. Faculty of Health Sciences Ben-Gurion University of the Negev: B.N. Publication House. Israel.

De Jonge, Ester Anthonina Leida (2016). What to eat for healthy bones?: epidemiological studies on diet, bone health and frailty. (degree of Doctor), Erasmus University Rotterdam,

Hossain, Md. Farid, Akhtar, Shaheen, \& Anwar, Mustafa. (2015). Nutritional Value and Medicinal Benefits of Pineapple. International Journal of Nutrition and Food Sciences, 4(1), 84-88.

Hyson, Dianne A. (2011). A Comprehensive Review of Apples and Apple Components and Their Relationship to Human Health. American Society for Nutrition. Adv. Nutr., 2, 408-420.

Jang, Hae-Dong, Hong, Jae-Young, Han, Kyungdo, Lee, Jae Chul, Shin, Byung-Joon, Choi, Sung-Woo, . . B Bang, Chungwon. (2017). Relationship between bone mineral density and alcohol intake: A nationwide health survey analysis of postmenopausal women. PLoS ONE, 12(6), 1-11.

Joy, P P. (2010) Benefits and uses of pineapple. In. Vazhakulam-686 670, Muvattupuzha, Ernakulam District, Kerala, India: Pineapple Research Station (Kerala Agricultural University).

Kim, Bongju , Sung-Ho Lee, Su-Jin Song, Won Hyeon Kim, Eun-Sung Song, Jae-Chang Lee, ... Jong-Ho Lee. (2019). Protective Effects of Melon Extracts on Bone Strength, Mineralization, and Metabolism in Rats with Ovariectomy-Induced Osteoporosis. Antioxidants, 8(306), 1-14.

Kruger, Marlena C, \& Wolber, Frances M. (2016). Osteoporosis: modern paradigms for last century's bones. Journal of Nutrients, 8(6), 376.

Maheshwari, Raaz K, Mohan, Lalit, Malhotra, Jayant, Updhuay, Bhavana , \& Rani, Bina. (2014). Invigorating Efficacy of Cucumis Sativas for Healthcare \& Radiance. International Journal of Chemistry and Pharmaceutical Sciences, 2(3), 737-744.

Muthama, Thomas Mutinda (2018a). Factors Influencing Households Health Status in Machakos County, Kenya. The International Journal Of Humanities \& Social Studies, 6(12), 1-13.

Muthama, Thomas Mutinda (2018b). Household Production of Human Health in Kenya: An Econometric Analysis. International Journal of Science and Research (IJSR), 7(12), 960-965.

Naughton, Geraldine, Greene, David, Courteix, Daniel, \& Baxter-Jones, Adam. (2017). Resilient, Responsive, and Healthy Developing Bones: The Good News About Exercise and Bone in Children and Youth. Journal of Pediatric exercise science, 29(4), 437-439.

Passali, C, Patsaki, A, Lelovas, P, Aligiannis, N, Makropoulou, M, Kourkoulis, S., . . Dontas, I. (2019). Red wine polyphenols modulate bone loss in the ovariectomized rat model of postmenopausal osteoporosis. Journal of the Hellenic Veterinary Medical Society, 70(2), 1541-1550.

Settaluri, V. S, Kandala, C. V. K, Puppala, N, \& Sundaram, J. (2012). Peanuts and Their Nutritional Aspects-A Review. Food and Nutrition Sciences, 3, 1644-1650. 
The Holy Book. (1982a). Ephesians 5:18. In New Living Translation (NLT). Nashville, TN: Thomas Nelson Publishers.

The Holy Book. (1982b). Ist Timothy 5:23. In New King James Version (NKJV). Nashville, TN: Thomas Nelson Publishers.

The Holy Book. (1982c). Job 4:14. In New King James Version (NKJV). Nashville, TN: Thomas Nelson Publishers.

The Holy Book. (1982d). Leviticus 17:11. In New King James Version (NKJV). Nashville, TN: Thomas Nelson Publishers.

The Holy Book. (1982e). Proverbs 15:30. In New King James Version (NKJV). Nashville, TN: Thomas Nelson Publishers.

Troy, Karen L, Mancuso, Megan E, Butler, Tiffiny A, \& Johnson, Joshua E (2018). Exercise early and often: effects of physical activity and exercise on women's bone health. International Journal of Environmental Research and Public Health, 15(5), 878.

US Department of Health Human Services. (2004). Bone health and osteoporosis: a report of the Surgeon General. Retrieved from Rockville MD Washington DC:

Walther, Barbara, Schmid, Alexandra, Sieber, Robert, \& Wehrmuller, Karin. (2008). Cheese in nutrition and health. Dairy Science and Technology, 88 389-405. 